\title{
Optimization of isolated and combined pad foundation using computer aided application of finite element approach
}

\author{
Ubi Stanley E. * \\ Department of Civil Engineering, Cross River University of Technology, Calabar, Nigeria.
}

Global Journal of Engineering and Technology Advances, 2021, 06(03), 024-041

Publication history: Received on 20 January 2021; revised on 23 February 2021; accepted on 25 February 2021

Article DOI: https://doi.org/10.30574/gjeta.2021.6.3.0030

\begin{abstract}
Most Finite Element packages provide means to generate meshes automatically. However, the user is usually confronted with the problem of not knowing whether the mesh generated is appropriate for the problem at hand. Since the accuracy of the Finite Element results is mesh dependent, mesh selection forms a very important step in the analysis of isolated and combined footing pad foundation. SAFE is an ultimate tools use in the design of concrete floors and foundation system, hence provide a suitable means for the user. From framing layout all the way through to detail drawing production, SAFE integrate every aspect of engineering design which are in one process easy and intuitive environment. SAFE provides unmatched benefits to the engineer with its truly unique combination of power, comprehensive capabilities, and ease-of-use. In the context of this research, we have plotted graphs showing the relationship between the nodes and displacement with the stress patterns as generated from the software. It is understood from the graph that multiple elements in the process of meshing will make the footing to be at equilibrium. The research also carry the shape deformed diagram which shows the deformation of the footing due to the impose load (stress) on the footing, it also give the bending moment diagram of the footings. The basic structure and analysis of the single and double pad footing foundations have been designed using Finite Element Analysis (FEA) with the failure planes being considered. The results obtained, it is assumed that FEA is an ideal design method that breaks foundation design into basic elements and nodes that shows the action of the loading on the footings.
\end{abstract}

Keywords: Safe; Finite; Mesh; Foundation; Footing

\section{Introduction}

The foundation of a structure is the element of that structure which connects it to the ground, and transfers loads from the structure to the ground, it is sometimes considered as either shallow or deep. Hence by so doing, foundation is given a greater value in the recent years till date, Kumar et al (2015). The application of soil mechanics and rock mechanic (geotechnical engineering) in the design of foundation element in a structure. The finite element method is such a widely used analysis-and-design technique that it is essential that undergraduate engineering students have a basic knowledge of the theory and applications of the technique (Hutton, 2015). Hence it is very important in geotechnical engineering in the following ways; mostly failure analysis (what will be the failure plane in the soil mass when the foundation is loaded. How far will it extend? How far would it affect?), for analysis of rock fractures, for analyzing the forces in retaining walls and settlement of foundation, would piling affect the adjacent existing buildings and failure can happen due to pore pressure. Specifically shallow foundation (pad) are used to support individual point load such as that directly from the superstructure to the receiving soil strata, hence the construction of this type of foundation is based upon some certain facts which govern it, this facts are soil type and nature of load as stated by Kumar et al (2015). Foundation is the most important part of the structure and by so doing it must be given a serious attention in the design and construction. Finite Element Analysis is a very accurate means compare to other means in the (analysis) of a footing,

\footnotetext{
${ }^{*}$ Corresponding author: Agbor RB

Environmental Biotechnology Unit, Department of Genetics and Biotechnology, University of Calabar, Calabar, Nigeria.
} 
or foundation. Finite element analyses have also proved very useful for planning instrumentation studies by showing where objects can be located to best advantage through meshing, which is the primary aim of finite element. Fattah et al., (2017) state that this type of foundation is often used when the structural load will not cause excessive settlement of the underlying soil layers. In general, shallow foundations are more economical to construct than deep foundations. Pad foundations are used to support an individual point load such as that due to a structural column. Kharagpur (2017) pad foundations are shallow foundation used to support an individual point load such as that which is transfer from the super structure due to the structural column. They are spread footings, single footings or double footings which are may be circular, square or rectangular. They usually consist of a block or slab of uniform thickness, but they may be stepped if they are required to spread the load from a heavy column. Farrokhzad, et al (2011), a node is a specific point in the finite element at which the value of the field variable is to be explicitly calculated. Exterior nodes are located on the boundaries of the finite element and may be used to connect an element to adjacent finite elements. Nodes that do not lie on element boundaries are interior nodes and cannot be connected to any other element. Soil is considered by the engineer as a complex material produced by the weathering of the solid rock. Soil is the most important material which is in use for construction of civil engineering structures (Kouzer and Kumar, 2010). Among all parameters, the bearing capacity of soil to support the load coming over its unit area is very important. Principal factors that influence ultimate bearing capacities are type of soil, width of foundation, soil weight in shear zone and surcharge. Structural rigidity and the contact stress distribution do not greatly influence bearing capacity. Bearing capacity analysis assumes a uniform contact pressure between the foundation and the underlying soil. With other factors unchanged the type of failure of soil, depth of foundation and effect of water table also govern the bearing capacity of the soil (Madan et al. 1989). Similarly the effect of depth of footing on bearing capacity of soil is studied. In general, other factors remain constant, bearing capacity of soil goes on increasing as depth or width of foundation increases. In case of local shear failure, amongst different shapes of footing is found to be lowest in comparison with square, circular and rectangular shaped footings. The aim of the study was to model isolated and combined pad footing using computer aided application of finite element approach.

\section{Material and methods}

\subsection{Study Area}

This work is based on optimization for single and combined footings (Pad foundation) using Finite Element Analysis. The general techniques and terminology of finite element analysis will be introduced with reference to depict a volume of some material(s) having known physical properties. The volume represents the domain of a boundary value problem to be solved. Note that this implies that an exact mathematical solution is obtained; that is, the solution is a closed-form algebraic expression of the independent variables. In practical problems, the domain may be geometrically complex as is, often, the governing equation and the likelihood of obtaining an exact closed-form solution is very low. Therefore, approximate solutions based on numerical techniques and digital computations are most often obtained in engineering analyses of complex problems. Finite element analysis is a powerful technique for obtaining such approximate solutions with good accuracy. Hence foundation of a structure require a reliable soil to enable it to withstand the proposed structure, necessary measures are taken to ensure that a suitable soil is been chosen in other to acquire a suitable design status.

\subsection{Foundation Modelling}

The footings were assumed to be founded on clay with un-drained shear strength of $100 \mathrm{kPa}$. This value is typical residual clay which has vane shear strengths in the range of 70 to $120 \mathrm{kPa}$. For earthquake loading the un-drained shear strength will be greater because of the rate of loading. We observed an increase of about $40 \%$ in the un-drained shear strength of this soil when tested at rates of loading comparable to those during a seismic event. Thus the value of $100 \mathrm{kPa}$ used herein for earthquake loading was equivalent to the lower end of the range of values found in normal site investigation. Hence the factors considered while modeling this foundation are listed below;

- Energy Dissipation Mechanism and,

- $\quad$ Factor of Safety

\subsubsection{Energy dissipation mechanism}

The dynamic response of a structure depends on its mechanical properties and the characteristics of the induced excitation. Mechanical properties which are efficient to mitigate the structure's response when subjected to certain inputs might have an undesirable effect during other inputs. Ground motions vary significantly from one another in amplitude, frequency content and duration. Those characteristics are influenced by source mechanism and travel path 
and modified by local geological and soil conditions. The ability to dissipate the induced energy is crucial to the earthquake resistance of a structure. Various energy dissipation mechanisms have been proposed to enhance structural response (Oyenuga 2001). These energy dissipation mechanisms can be of various types such as viscous, rigid-plastic, elastoplastic, viscoplastic, or combination of them.

\subsubsection{Factor of safety}

Where earthquake loads are included, the minimum safety factor for the foundation shall be 1.1. "The 2012 IBC Code and Commentary, volume 2, states the following: "the safety factor for stability of foundations predates the development of load combination.

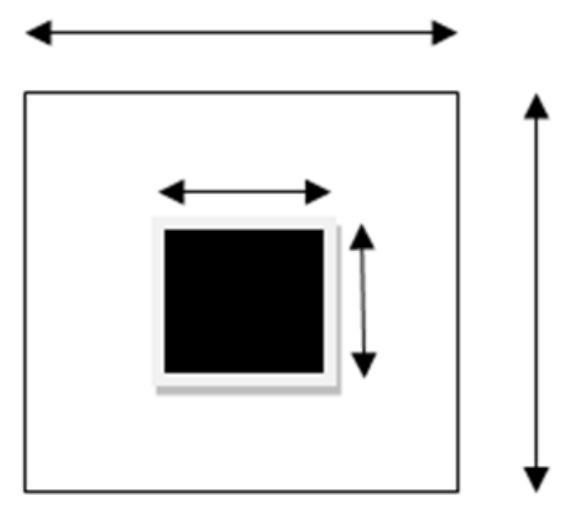

Figure 1 Single footing

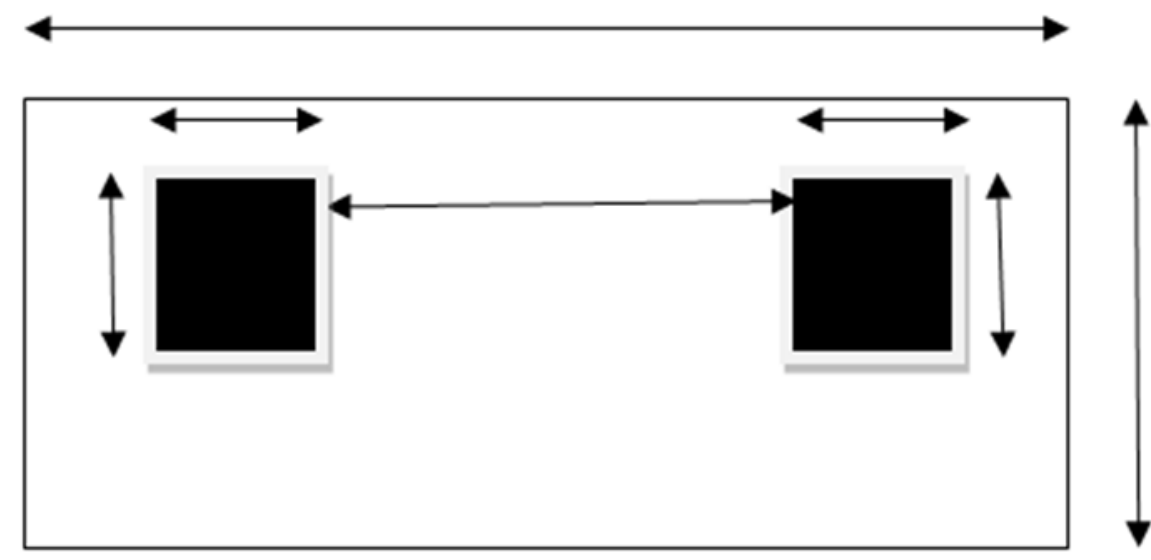

Figure 2 Double footings

\subsection{Fem Formulations (Using $\mathrm{H}$ - Mesh)}

\subsubsection{Mesh Generation}

Each element in the finite element model is addressed by its number. Also each node is addressed by its number. The inter-connectivity of the elements is determined by the common nodes shared by the elements. In a model with few elements and nodes, the user can manually divide the domain, number each element and node, and keep track of the element connectivity, hence this process is called mesh generation. However, in models with many nodes and elements, the effort required to divide the domain into elements and attend to connectivity is great. It then becomes difficult to accomplish this task without committing errors. However, there are several finite element preprocessors which do this job automatically once the geometry is defined (Bowles 1997). Users can then devote more time to interpreting results. Shephard has reviewed the current trends in mesh generation. Although there are several ways to generate meshes, these methods fall into two broad categories: 


\subsubsection{Mapping techniques}

This type of mesh generation is best suited when the geometry is simple - as in the case of a rectangle or a cuboid. Typically the user needs to choose the number of elements on each of the edges that defines the geometry and the element concentration along the edges. The software then generates the mesh simply by joining nodes on the opposite edges. The software considered here is SAFE to generate the mesh.

\subsubsection{Free mesh generation}

This method of generation is best suited for models with complicated geometry. SUPERTAB has this capability. The model is broken down into sub-areas and sub-volumes. On each of the curves of every sub-area and sub-volume the number of elements and their concentrations are selected. The software then generates a mesh that is consistent with the selected values and satisfies the requirement on the aspect ratios and the distortion factors of the elements

Hence the mesh generation method considered here is mapping techniques, were we choose a rectangular footing base for double footings, with dimension $2000 \mathrm{~mm}$ by $4050 \mathrm{~mm}$ and rectangular footing base for single footings with dimension $2400 \mathrm{~mm}$ by $2800 \mathrm{~mm}$. were the maximum mesh size for both footings is $200 \mathrm{~mm}$, and was generated with the aid of a software safe, as will be discuses in chapter four of this work.

\subsection{Data Analysis}

The objective is to develop a practical and efficient procedure of single and double footing (Pad foundation) with computer aided application using Finite Element Approach (David 2004). The thesis is that for many problems the minimization of the trace of the stiffness matrix with respect to the nodal coordinates, leads to a minimization of the potential energy, and as a consequence, provides the optimal grid configuration. The research work is regular shaped concrete footings, with overall dimensions of, for single footing length of $2800 \mathrm{~m}$ width of $2400 \mathrm{~m}$ with a $450 \mathrm{~mm}$ column centered, for double footings length of $4050 \mathrm{~mm}$ width of $2000 \mathrm{~mm}$ with two columns of $450 \mathrm{~mm}$ spaced at $2500 \mathrm{~mm}$.

\section{Procedures in Carrying out Data Analysis using SAFE (software):}

\subsection{Step 1: Begin a new model}

Launch the software and open new model, then it pops out new model initialization form. From the form we choose the design code i.e. B.S8110 and unit in metric. In this Step, the dimensions and basic grid will be defined, which will serve as a guide for developing the model.

- Click the File menu > New Model command to access the New Model Initialization form. This form is used to specify the starting point of the model creation: a Blank screen, a screen with a Grid Only, or one of eight templates. Default units also may be selected here, along with the design code and preferences.

- In the Design Data area, select B.S 8110, 1997 from the Design Code drop-down list.

- In the Design Data area, verify that the Units are set to Currently US; if not, click the Modify/Show button and select the U.S. Defaults on the Units form.

- In the Initial Model area, for single footing click the single footing button and for double footings click the double footings button to display the footing drop box and edit the following; along $\mathrm{X}$ direction, left and right edges distance $0.9 \mathrm{~m}$ each, along Y direction, top and bottom edge distance $1.2 \mathrm{~m}$ each, load size $600 \mathrm{~mm}$ for double footings spacing $2.5 \mathrm{~m}$ loads, dead $30 \mathrm{KN}$ live $45 \mathrm{KN}$ for double footings load one and two are the same, footing thickness $500 \mathrm{~mm}$, surcharge modulus say $18000 \mathrm{KN} / \mathrm{M}^{3}$ then click ok.

- Save your model often! Click the File menu > Save or save as command. Specify the directory in which to save the model. For this research, the file name as footing design.

\subsection{Step 2: Define the material}

In this Step, material and section properties for the footings (area object), columns, (line object) are defined.

- Click the Define menu > Materials command to access the Materials. 
- Highlight 4000Psi in the Materials area, and click the Modify/Show Material button to display the Material Property Data form. That form lists the properties associated with 4000psi concrete; this is the concrete property that will be used in our model.

- Click the OK button to accept this material as defined.

- In the Materials area, highlight A615Gr60.

- Click the Modify/Show Material button to display the Material Property Data form. This form lists the properties associated with Grade 60 reinforcing; this is the rebar property that will be used in our model.

- Click the $\mathbf{O K}$ button to accept this material as defined.

- $\quad$ Click the $\mathbf{O K}$ button on the Materials form to accept all of the defined materials.

- $\quad$ Click the File menu > Save command to save your model.

\subsection{Define column property}

- $\quad$ Click the Define menu > Column Properties command to access the Column Properties form.

- In the Column Property area, highlight COL1

- Click the Modify/Show Property button to access the Column Property Data form. Recall that the columns for this research are $450 \mathrm{~mm}$ square and that the drop panels are $0.9 \mathrm{~m}$ by $1.2 \mathrm{~m}$ square.

- In the Column Section Dimensions area, select Rectangular from the Column Shape drop-down list

- In the Column Section Dimensions area, type 450mm into the Parallel to 2-Axis edit box and type 450mm into the Parallel to 3-Axis edit box.

- Make sure that the Include Automatic Rigid Zone Area over Column option is checked. This option restricts deformation of the slab at the column location, which prevents unrealistic peaks in moment distribution from occurring.

- In the automatic drop down area check these include automatic drop panel over column option. This option automatically adds a drop panel when a column with this property is drawn.

- In the Automatic Drop Panel Dimensions area, type $\mathbf{9 0 0} \mathbf{m m}$ into the Parallel to 2-Axis edit box and type 1200mm into the Parallel to 3-Axis edit box.

- In the Automatic Drop Panel Dimensions area, select DROP from the Slab Property drop-down list.

- Click the OK button to leave the Column Property Data form.

- Click the Add New Property button to access the Column Property Data form.

- In the General Data area, type COL2 in the Property Name edit box.

- In the Column Section Dimensions area, select Rectangular from the Column Shape drop-down list

- In the Column Section Dimensions area, type 450mm into the Parallel to 2-Axis edit box and type 450mm into the Parallel to 3-Axis edit box.

- Make sure that the Include Automatic Rigid Zone Area Over Column option is checked

- In the Automatic Drop Panel Dimensions area, make sure that the Include Automatic Drop Panel Over Column option is unchecked

- Click the OK button to leave the Column Property Data form.

- $\quad$ Click the $\mathbf{O K}$ button to accept the Column Property definitions

\subsection{Step 3: Define statics load pattern}

In this Step, the dead and live static load patterns are defined. That is, we will name the various types of loads and specify the self-weight multipliers. The loads will be assigned to objects, and the values for the loads specified (uniform dead load of $30 \mathrm{kN} / \mathrm{m}^{2}$ and live load of $50 \mathrm{kN} / \mathrm{m}^{2}$ ), in Step 8 .

- Click the Define menu > Load Patterns command to access the Load Patterns form

- Note that load patterns DEAD and LIVE are defined by default 
- $\quad$ Recall that the project will be analyzed for the dead load plus the self-weight of the structure. Thus, the Self Weight Multiplier should be set equal to 1 (this will include 1.0 times the self-weight of all members) for the DEAD load. Only the DEAD load pattern should have a non-zero Self Weight Multiplier.

- $\quad$ Click the $\mathbf{O K}$ button to accept the defined static load patterns

\subsection{Step 4: Define load cases}

In this Step, the Load Cases are defined. This is where the type of analysis is specified.

- $\quad$ Click the Define menu > Load Cases command to access the Load Cases form

- With the DEAD Load Case Name highlighted, click the Modify/Show Case button to display the Load Case Data form. This data form changes based on the type of load case specified.

- In the Load Case Type area, select Static from the drop-down list. Modal and Hyper static also are available as load case types

- In the Analysis Type area, select the linear option. When working with a Static Load Case Type, the program offers the option to do Linear, Nonlinear (Allow Uplift), Nonlinear (Cracked), or Nonlinear (Long Term Cracked) analysis. For our tutorial example, a Static, Linear analysis will be performed for DEAD and LIVE

- In the Loads Applied area, verify that the load pattern is DEAD with a scale factor of $\mathbf{1}$.

- Click the OK button to close the Load Case Data form

- Review the LIVE load case, if so desired, by selecting it and using the Modify/Show Case button as described for the DEAD load case

- $\quad$ Click the $\mathbf{O K}$ button to close the Load Cases form

- $\quad$ Click the File menu > Save command

\subsection{Step 5: Draw Object}

In this step, column with drop will be drawn with the active window set (i.e., Plan View window active and the snap to points and grid intersections enabled), use the following Action Items to draw columns.

- $\quad$ Click the Draw menu > Draw Columns command to access the Draw Columns form

- Click in the Property Below drop-down list and select COL1. This is the property for the $450 \mathrm{~mm}$ by $450 \mathrm{~mm}$ column with a drop panel defined in Step 2.

- Click in the Property Above drop-down list and select NONE. There are no columns above the slab.

- Click in the Height Below edit box and type 12, and click in the Height Above edit box and type 0. Note that the units are meter.

- $\quad$ Click in the Cardinal Point drop-down list and select 10 (Centroid).

- Locate the mouse cursor at a distance of $0.9 \mathrm{~m}$ from the left inside the footing and click, for double footing do the same for the two columns with distance of $2.5 \mathrm{~m}$ apart

- $\quad$ Click on the Select menu > Select > Pointer/Window command or press the Esc key on the keyboard to exit the Draw Columns command.

- Locate the mouse cursor just above and to the left of grid intersection C6, hold down the left mouse button, and drag diagonally to just below and to the right of D5 and release the mouse button. The status bar in the lower left-hand corner should show "2 Points, 1 Lines, 1 Areas, 4 Edges selected." For single footing, and "4 Points, 2 Lines, 2 Areas, 8 Edges Selected." If the selection is not correct, simply click the Select menu > Clear Selection command and try again.

- $\quad$ Click the Edit menu > Delete command or press the Delete key on the keyboard to remove the columns enclosed in the window.

- $\quad$ Click the File menu > Save command to save your model.

- $\quad$ Click the View menu > Set Default 3D View command to display the model in 3D. Note how the columns extend below the slab.

- $\quad$ Click the View menu > Set Plan View command to return to the Plan View before continuing the project. 


\subsection{Step 6: Add Design Strip}

In this step, design strips will be added to the model. Design strips determine how reinforcing will be calculated and positioned in the slab. Forces are integrated across the design strips and used to calculate the required reinforcing for the selected design code (Satis and Santhian 2010). Typically design strips are positioned in two principal directions: Layer A and Layer B. Similar to the previous sections, ensure that the Plan View is active and the snap to points and grid intersections features are enabled. Add design strips to the model as follows:

- $\quad$ Click the Edit menu > Add/Edit Design Strips > Add Design Strips command to display the Add Design Strips form

- In the Options area, select the Add Design Strips along Cartesian Grid Lines option. Make sure that the Include Middle Strip option is checked

- In the Parameters area, click in the Grid Direction drop-down list and select $\mathbf{X}$.

- Select A from the Strip Layer drop-down list.

- Select the Auto option. The added design strips will automatically adjust their width to align with adjacent strips

- Click the OK button to leave the Add Design Strips form. Design strips in the X-axis direction should now appear as solid lines.

- Left click on the design strips that lie below grid line 3 to select them; the status bar in the lower left-hand corner should show "4 Design Strips selected." If the selection is not correct, simply click the Select menu > Clear Selection command and try again

- Left click on the slab (anywhere except at a column or design strip location) to select it; the status bar in the lower left-hand corner should now show "1 Areas, 6 Edges, 4 Design Strips selected."

- Left click at the left ends of the 4 selected design strips; the status bar in the lower left-hand corner should now show "4 Points, 1 Areas, 6 Edges, 4 Design Strips selected."

- Click the Edit menu > Align Points/Lines/Edges command to display the Align Points/Lines/Edges form

- Select the Trim Line/Edge/Tendon/Strip Objects option.

- Click the $\mathbf{O K}$ button to leave the Align Points/Lines/Edges form. The design strips below grid line 3 should now be trimmed to the edge of the slab.

- Left click on the design strip that lies on grid line 5 to select it; the status bar in the lower left-hand corner should show "1 Design Strips selected."

- Press the Delete key on the keyboard to remove the selected design strip from the model.

- Click the Draw menu > Draw Design Strips command to display the Draw Design Strips form

- Select A from the Strip Layer drop-down list

- Select Column Strip from the Strip Design Type drop-down list.

- Type 4.5 into the Start Width Left edit box.

- Type 6 into the Start Width Right edit box.

- Type 4.5 into the End Width Left edit box and type 6 into the End Width Right edit box.

- Left click at grid intersection A5 and at C5, and then click the right mouse button to stop drawing.

- Left click at grid intersection D5 and at F5.

- Press the Esc key on the keyboard to leave the Draw command

- $\quad$ Click the Edit menu > Add/Edit Design Strips > Add Design Strips command to display the Add Design Strips form.

- $\quad$ Select Y from the Grid Direction drop-down list.

- Click in the Strip Layer edit box and select B from the drop-down list.

- Click the OK button to leave the Add Design Strips form. Design strips in the Y-axis direction should now appear as solid lines.

- Left click on the design strips that lie to the left of grid line D to select them; the status bar in the lower lefthand corner should show "2 Design Strips selected."

- Left click on the slab (anywhere except at a column, drop panel, beam or design strip location) to select it; the status bar in the lower left-hand corner should now show "1 Areas, 4 Edges, 2 Design Strips selected." 
- Left click at the bottom ends of the selected design strips; the status bar in the lower left-hand corner should now show "2 Points, 1 Areas, 4 Edges, 2 Design Strips selected."

- Click the Edit menu > Align Points/Lines/Edges command to display the Align Points/Lines/Edges form.

- Select the Trim Line/Edge/Tendon/Strip Objects option.

- Click the OK button to leave the Align Points/Lines/Edges form. The Y direction design strips to the left of grid line D should now be trimmed to the edge of the slab.

- The trimming of the design strips was done for display purposes only; the program will automatically ignore the portion of a design strip that extends beyond a slab edge.

- Click the File menu > Save command to save your model.

\subsection{Step 7: Display option}

In this Step, the set display options will be used to alter the objects displayed.

- $\quad$ Click the View menu > Set Display Options command. When the Set Display Options form displays, uncheck the Design Strip Layer A and Design Strip Layer B check boxes in the Items Present in View area, this action will turn off the display of the design strips.

- Click the OK button to accept the changes, and the model now appears

\subsection{Step 8: Assign load}

In this Step, the dead and live loads will be assigned to the slab. Ensure that the Plan View is still active, and that the program is in the select mode (Draw menu > Select > Pointer/Window command).

- Select the slab by clicking on it anywhere that is not a beam, wall, column, drop panel or opening. The status bar in the lower left hand corner should show "1 Areas, 4 Edges selected." click the Select menu > Clear Selection command, and try again in case of mistakes.

- Click the Assign menu > Load Data > Surface Loads command to access the Surface Loads form

- If it is not selected already, select DEAD from the Load Pattern Name drop-down list.

- Select Gravity from the Direction drop-down list in the Load Direction area.

- In the Uniform Loads area, type 30 in the Uniform Load edit box. Note: Additional load patterns may be defined by clicking on the "..." button next to the load pattern name. A "..." button returns you to the form used to define the item in the adjacent drop-down list or edit box, which in this case is the Load Patterns form.

- Click the OK button to accept the dead load assignment. SAFE will display the loads on the model. Use the Assign menu > Clear Display of Assigns command to remove the assignments from the display, if desired

- Click anywhere on the main slab to reselect the slab, or click the Select menu > Get Previous Selection command to select the slab.

- Click the Assign menu > Load Data > Surface Loads command to again access the Surface Loads form.

- Select LIVE from the Load Pattern Name drop-down list.

- Type 50 in the Uniform Load edit box in the Uniform Loads area.

- Click the $\mathbf{O K}$ button to accept the live load assignment. Again, use the Assign menu > Clear Display of Assigns command to remove the assignments from the display.

- To review the assignments to the slab, right click on the slab anywhere that is not a beam, wall, column, droppanel or opening to access the Slab-Type Area Object Information form

- Select the Loads tab and note that the DEAD Load Pattern has a Load Value of $\mathbf{3 0 K N} / \mathbf{M}^{2}$, and that the LIVE Load Pattern has a Load Value of $\mathbf{5 0 K N} / \mathbf{M}^{2}$

- Click the $\mathbf{O K}$ button to close the Slab-Type Area Object Information form.

- Click the File menu > Save command to save your model.

\subsection{Step 9: Run Analysis and Design}

In this Step, the analysis and design will be run 
- Click the Run menu > Run Analysis \& Design command to start the analysis. The program will create the analysis model from your object-based SAFE model and will display information in the status bar in the lower left-hand corner as the analysis and design proceeds. Additional information about the run may be accessed at a later time using the File menu > Show Input/output Text Files command and selecting the filename with a .LOG extension.

- When the analysis and design are finished, the program automatically displays a deformed shape view of the model, and the model is locked. The model is locked when the Options menu > Lock/Unlock Model icon appears depressed. Locking the model prevents any changes to the model that would invalidate the analysis results

\subsection{Step 10: Graphically Review the Analysis Results}

In this Step, the analysis will be reviewed using graphical displays of the results

- Click the View menu > Set Default 3D View command to display the deformed shape for the DEAD load case in 3D.

- Click the Start Animation button in the lower right-hand corner of the display to animate the deformed shape. Speed of the animation may be adjusted by using the slider control adjacent to the button. Click the Stop Animation button to end the animation

- Click the Display menu > Show Deformed Shape command to access the Deformed Shape form

- In the Load Case/Load Combination area, select the Load Case option.

- Select LIVE from the Load Case drop-down list.

- Select the Automatic option in the Scaling area.

- Check the Draw Contours checkbox in the Contour Range area.

- Click the OK button to generate a 3-D deformed shape with contours for the LIVE load case

- Click the Display menu > Show Slab Forces/Stresses command to bring up the Slab Forces/Stresses form

- Select LIVE from the Load Case drop-down list

- Select the Resultant Forces option in the Component Type area.

- Select the M22 option in the Component area.

- Select the Display Contours on Deformed Shape option in the Display Options area

- Click the OK button to generate the moment diagram Note that as you move the cursor over the moment diagram, the values are displayed at the cursor and in the lower left-hand corner of the window.

- Click the Display menu > Show Under-form Shape command to clear the display of the moment diagram.

- $\quad$ Click the View menu > Set Plan View command to return to the Plan View.

\subsection{Step 11: Design Display}

In this Step, design results for the slab and beams will be displayed. Note that the design was run along with the analysis in Step 9. Design results are for the B.S 8110, 1997 code, which was selected in Step 1. Design preferences may be reviewed or changed by going to the Design menu > Design Preferences command (some design preferences are also set on the section property data forms); be sure to re-run the analysis and design (Step 9) if changes to the preferences are made.

- Click the Display menu > Show Slab Design command to access the Slab Design form

- In the Choose Display Type area, select Finite Element Based from the Design Basis drop-down list. This option displays the required reinforcing calculated on an element-by-element basis as intensity contours integration across the defined design strips is not performed.

- In the Reinforcing Direction and Location area, select the Direction 2 - Bottom Rebar option. Direction 2 refers to the object local axis 2 direction.

- In the Show Rebar above Specified Value area, select the Non option.

- Click the OK button to leave the Slab Design form and display the slab design results for the local axis 2 direction. Again, positioning the cursor anywhere on the slab will result in the display of the reinforcing values at the cursor and in the lower left-hand corner of the SAFE window. 


\subsection{Step 12 Run Detailing}

In this Step, detailing will be run and displayed. Detailing may be run only after analysis and design are complete.

- Click the Detailing menu > Detailing Preferences command to display the Detailing Preferences form. Use this form to set the regional standards, to control how dimensioning is displayed, to manage reinforcing bar notation, and to select the units for material quantity takeoffs.

- Review the settings on this form (we will accept the default selections), and then click the $\mathbf{O K}$ button to close the form.

- Click the Detailing menu > Footings Preference command to display the footing preference form.

- Click the General and Display tab. On this tab review or alter the rebar curtailment, detailing and callout options, as well as set how sections should be cut. We will accept the default settings.

- Click the Rebar Selection tab and review or change the rebar selection rules, preferred sizes, minimums and reinforcing around openings. We will accept the default settings.

- Click the $\mathbf{O K}$ button to accept the selections and close the form.

- Click the Detailing menu > Drawing Sheet Setup command to display the Drawing Sheet Setup form. The sheet size, scales, title block and text sizes can be reviewed and changed using this form. We will accept the default settings.

- Click the $\mathbf{O K}$ button to close the form.

- Review the line thicknesses and styles by clicking the Detailing menu > Drawing Format Properties command.

- Click the $\mathbf{O K}$ button to accept the selections and close the form.

- Now that the detailing preferences and drawing setup options have been reviewed, click the Run menu > Run Detailing command to generate the detailing drawings. A framing plan is displayed when detailing is complete.

- Click the Detailing menu > Show Detailing command to access the Display Detailing Item form.

- Select the Drawing option.

- Select Slab Rebar Plan - Bottom Bars from the Drawing dropdown list.

- Click the $\mathbf{O K}$ button to leave the Display Detailing Item form and display the selected drawing.

- Clicking on the Detailing tab in the Model Explorer and expanding the Views and Drawing Sheets trees also provides access to detailing drawings and component views.

- Click the Display menu > Show Under-formed Shape command to return to the model.

\subsection{Step 13: Create Report}

In this Step, a report describing model input and output results will be created.

- Click the File menu > Report Setup command to display the Report Setup Data form.

- In the Report Output Type area, be sure that the RTF File option is selected.

- In the Report Items area, uncheck the Include Hyperlinked Contents checkbox.

- Click the $\mathbf{O K}$ button to leave the Report Setup Data form.

- Click the File menu > Create Report command to display the Microsoft Word Rich Text File Report form.

- Type footings (single/double) in the File name edit box and click the Save button. A report, with a cover written bold SAFE will come up which should be displayed in your word processor, and will be saved to your hard disk, SAFE, (2016)

\section{Refinement}

The user needs to select the number of nodes and elements in the model. The selection may be the one that leads to the best description of the domain geometrically. For example, footing surface of the single and double footings could be modeled by a series of interconnected concrete cube. The larger the number of concrete, the better is the model. The selection may also be based upon intuition, past experience and engineering judgment. The mesh obtained may be 
adequate in some cases. In other cases, especially when singularities are present, the mesh may not be adequate to obtain the results to the accuracy desired. In such cases, the meshes need to be refined.

There are three ways of refining a finite element mesh:

- The H-method: This method increases the number of elements and hence decreases the element size while keeping the polynomial order of the shape function constant.

- The P-method: This method increases the polynomial order of the interpolation function while keeping the number of elements in the model constant.

- The R-method: This method redistributes the nodes while keeping the element number and the polynomial order of the interpolation function constant.

But, our concern here is using H-method because the object have to be constant i.e. the shape then the element will increase thereby reducing the size of the element to best fit the mesh.

\section{Reference Analysis (Safe)}

\subsection{Overview of Safe}

SAFE is an ultimate tools use in the design of concrete floors and foundation system, hence provide a suitable means for the user. From framing layout all the way through to detail drawing production, SAFE integrate every aspect of engineering design which are in one process easy and intuitive environment. SAFE provides unmatched benefits to the engineer with its truly unique combination of power, comprehensive capabilities, and ease-of-use.

Laying out models is quick and efficient with the sophisticated drawing tools, or use one of the import options to bring in data from CAD, spreadsheet, or database programs. Slabs and foundations can be of any shape, and can include edges shaped with circular and spline curves.

Post-tensioning may be included in both slabs and beams to balance a percentage of the self-weight. Suspended slabs can included flat, two-way, waffle, and ribbed framing systems. Models can have columns, braces, walls and ramps connected from the floor above and below. Wall can be modeled as either straight or curved. Mats and foundations can include nonlinear uplift from the soil springs, and a nonlinear cracked analysis is available for slabs. Generating pattern surface loads is easily done by SAFE with an automated option. Design strips can be generated by SAFE or drawn in a completely arbitrary manner by the user, with complete control provided for locating and sizing the calculated reinforcement. Finite element design without strips is also available and useful for slabs with complex geometries.

Comprehensive and customizable reports are available for all analysis and design results. Detailed plans, sections, elevations, schedules, and tables may be generated, viewed, and printed from within SAFE or exported to CAD packages.

SAFE provides an immensely capable yet easy-to-use program for structural designers, providing the only tool necessary for the modeling, analysis, design, and detailing of concrete slab systems and foundations. (SAFE, 2016).

\section{Validation of finite element model (fem) using safe}

\subsection{Single footing}

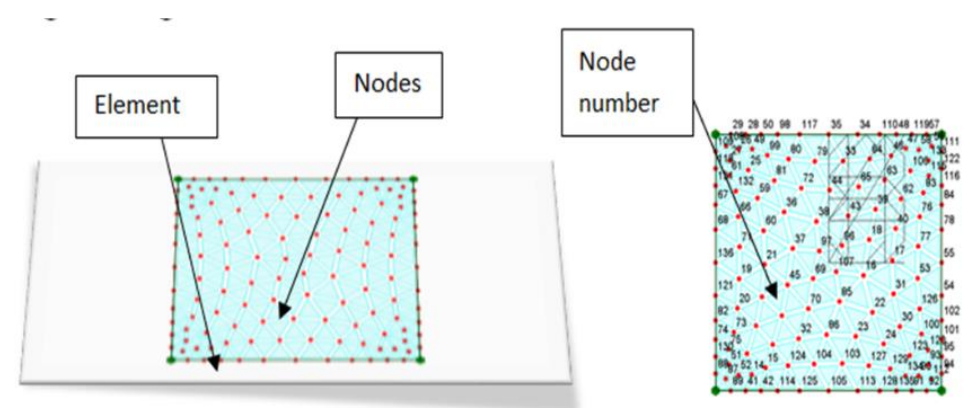

Figure 3 Finite element meshes illustrating the location of the applied load of $80 \mathrm{kN}$ 


\subsection{Double footings}
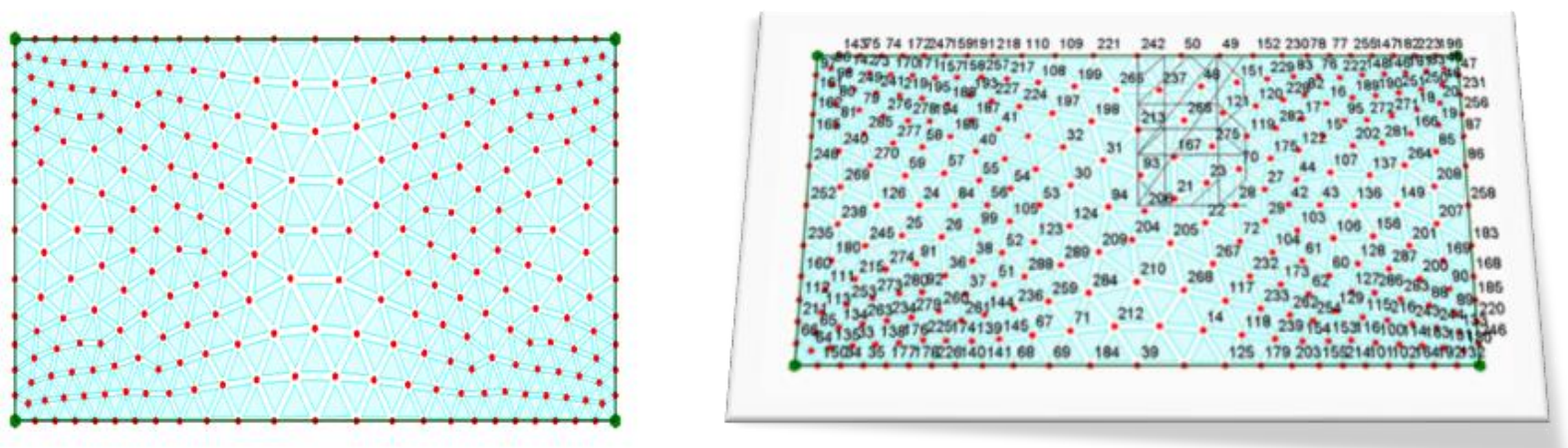

Figure 4 Finite elements mesh showing the element, nodes and node number

\section{Results and discussion}

\subsection{Loading}

Total load of $80 \mathrm{kN} / \mathrm{m}$ is applied on the footing, a uniformly distributed live load of $50 \mathrm{kN} / \mathrm{m}$ and distributed dead load of $30 \mathrm{kN} / \mathrm{m}$ although.

The table 1 above shows the nodal assemble masses of single footing as computed from SAFE 2016, this table gives the nodes and displacement at each node for the element.

Table 1 Single footing nodal assembly

\begin{tabular}{|l|l|l|l|l|l|l|l|}
\hline \multicolumn{2}{|c|}{ Assembled Nodal Masses For Single Footing } \\
\hline $\begin{array}{l}\text { Node } \\
\text { text }\end{array}$ & $\begin{array}{l}\text { Displacement } \\
\left(\mathrm{kN} / \mathrm{m}^{2}\right)\end{array}$ & $\begin{array}{l}\text { Node } \\
\text { text }\end{array}$ & $\begin{array}{l}\text { Displacement } \\
\left(\mathrm{kN} / \mathrm{m}^{2}\right)\end{array}$ & $\begin{array}{l}\text { Node } \\
\text { text }\end{array}$ & $\begin{array}{l}\text { Displacement } \\
\left(\mathrm{kN} / \mathrm{m}^{2}\right)\end{array}$ & $\begin{array}{l}\text { Node } \\
\text { text }\end{array}$ & $\begin{array}{l}\text { Displacement } \\
\left(\mathrm{kN} / \mathrm{m}^{2}\right)\end{array}$ \\
\hline 1 & 0.106651957 & 38 & 0.71253259 & 75 & 1.226959346 & 112 & 0.537740961 \\
\hline 2 & 0.234813553 & 39 & 0.752211825 & 76 & 1.274574427 & 113 & 0.299342468 \\
\hline 3 & 0.273351655 & 40 & 0.791891059 & 77 & 1.313935 & 114 & 0.34505045 \\
\hline 4 & 0.145190059 & 41 & 0.831570293 & 78 & 1.280038583 & 115 & 0.394701865 \\
\hline 23 & 0.628977677 & 42 & 0.871249527 & 79 & 1.198086861 & 116 & 0.416696626 \\
\hline 24 & 0.773892645 & 43 & 0.910928762 & 80 & 0.609798249 & 117 & 0.439012015 \\
\hline 25 & 0.854835273 & 44 & 0.950607996 & 81 & 0.293785812 & 118 & 0.458851633 \\
\hline 26 & 0.702719887 & 45 & 0.99028723 & 82 & 0.607288792 & 119 & 0.47869125 \\
\hline 27 & 1.163969102 & 46 & 1.023525867 & 83 & 0.806826537 & 120 & 0.498530867 \\
\hline 28 & 1.136497596 & 47 & 1.056123247 & 84 & 0.903549392 & 121 & 0.518370484 \\
\hline 29 & 1.210239806 & 48 & 1.001632163 & 85 & 0.94719655 & 122 & 0.538210101 \\
\hline 30 & 1.24491173 & 49 & 0.939254211 & 86 & 0.990843707 & 123 & 0.558049718 \\
\hline 31 & 3.004466296 & 50 & 0.478589455 & 87 & 1.034490865 & 124 & 0.577889335 \\
\hline 32 & 2.168171554 & 51 & 0.260266625 & 88 & 1.078138023 & 125 & 0.594004107 \\
\hline 33 & 3.520697618 & 52 & 0.540250419 & 89 & 1.12178518 & 126 & 0.609798249 \\
\hline 34 & 2.168171554 & 53 & 0.72638049 & 90 & 1.165432338 & 127 & 0.575741322 \\
\hline 17 & 0.222266264 & 54 & 0.822110183 & 91 & 1.209079496 & 128 & 0.537740961 \\
\hline 18 & 0.260266625 & 55 & 0.865757341 & 92 & 1.280038583 & & \\
\hline 19 & 0.30221042 & 56 & 0.909404498 & 93 & 1.131765475 & & \\
\hline & & & & & & & \\
\hline
\end{tabular}


Global Journal of Engineering and Technology Advances, 2021, 06(02), 024-041

\begin{tabular}{|l|l|l|l|l|l|l|l|}
20 & 0.323634246 & 57 & 0.953051656 & 94 & 0.575741322 & & \\
\hline 21 & 0.3453787 & 58 & 0.996698814 & 95 & 0.281417769 & & \\
\hline 22 & 0.365218318 & 59 & 1.040345971 & 96 & 0.580760238 & & \\
\hline 23 & 0.385057935 & 60 & 1.083993129 & 97 & 0.670383731 & & \\
\hline 24 & 0.404897552 & 61 & 1.127640287 & 98 & 0.767894092 & & \\
\hline 25 & 0.424737169 & 62 & 1.199592535 & 99 & 0.811750838 & & \\
\hline 26 & 0.444576786 & 63 & 1.064727102 & 100 & 0.856248841 & & \\
\hline 27 & 0.464416403 & 64 & 0.542222135 & 101 & 0.895928076 & & \\
\hline 28 & 0.48425602 & 65 & 0.30221042 & 102 & 0.93560731 & & \\
\hline 29 & 0.500941726 & 66 & 0.625930478 & 103 & 0.975286544 & & \\
\hline 30 & 0.517306804 & 67 & 0.72638049 & 104 & 1.014965778 & & \\
\hline 31 & 0.490957497 & 68 & 0.888397047 & 105 & 1.054645012 & & \\
\hline 32 & 0.460664756 & 69 & 0.941268859 & 106 & 1.094324247 & & \\
\hline 33 & 0.222266264 & 70 & 0.98888394 & 107 & 1.134003481 & & \\
\hline 34 & 0.462457226 & 71 & 1.036499021 & 108 & 1.166365799 & & \\
\hline 35 & 0.540250419 & 72 & 1.084114102 & 109 & 1.198086861 & & \\
\hline 36 & 0.625930478 & 73 & 1.131729183 & 110 & 1.131765475 & & \\
\hline 37 & 0.668910906 & 74 & 1.179344264 & 111 & 1.057557223 & & \\
\hline
\end{tabular}

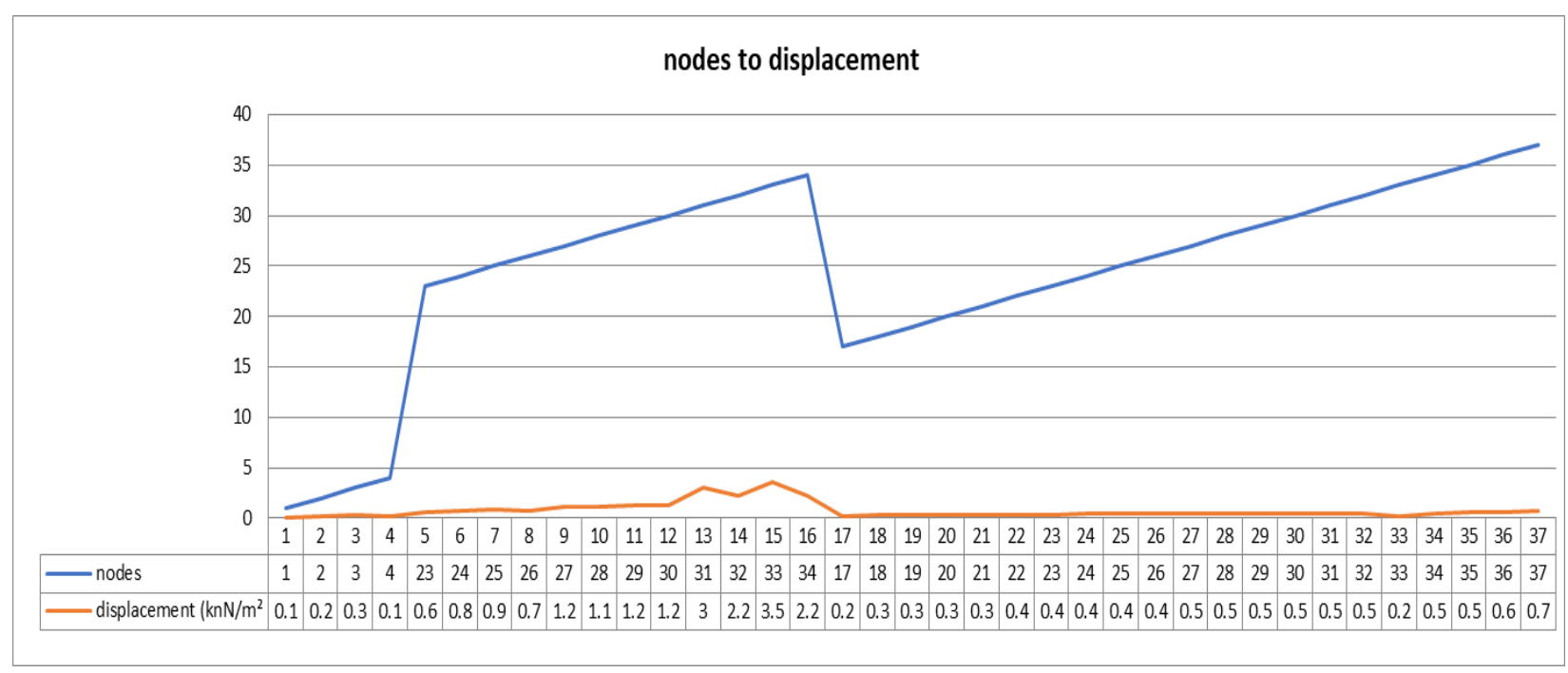

Figure 5 Nodes against displacement for isolated footing

The figure above show the graphical representation of the stated result in table; 1.0, this graph illustrate the displacement with node relationship as the displacement reach it maximum limit with a specified frequency with the node. Showing that at a high node, the displacement increases with increase in the node i.e. for the footing to be at equilibrium it should have a multiple node to enhance a reliable stress on the footing. 


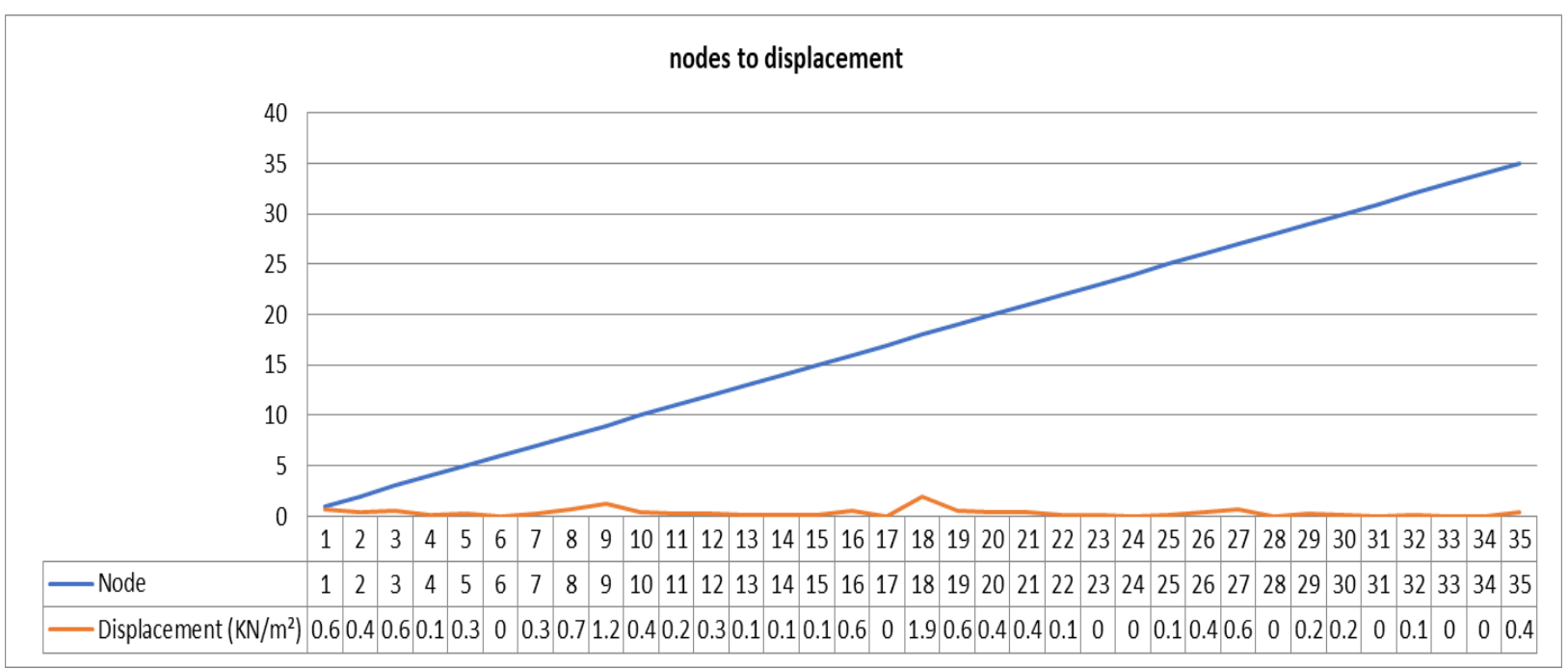

Figure 6 Nodes against displacement for combined footings

The table (2) shows the result of the double footings with the nodal assembly and the displacement at each node as computed from SAFE 2016.

Table; 2 shows the result of the stated Fig. 6 which is the graphical representation of Table 2, here the displacement move at uniform velocity and reaches its destination at the same frequency with the node.

Table 2 Double footings nodal assembly

\begin{tabular}{|c|c|c|c|c|c|}
\hline \multicolumn{6}{|c|}{ Assembled Nodal Masses For Double Footings } \\
\hline Node & $\begin{array}{l}\text { Displacement } \\
\left(\mathrm{KN} / \mathrm{m}^{2}\right)\end{array}$ & Node & $\begin{array}{l}\text { Displacement } \\
\left(\mathrm{KN} / \mathrm{m}^{2}\right)\end{array}$ & Node & $\begin{array}{l}\text { Displacement } \\
\left(\mathrm{KN} / \mathrm{m}^{2}\right)\end{array}$ \\
\hline 1 & 0.62 & 36 & 0.123 & 69 & 0.151 \\
\hline 2 & 0.364 & 43 & 0.036 & 70 & 0.211 \\
\hline 3 & 0.592 & 44 & 0.395 & 71 & 0.024 \\
\hline 4 & 0.06 & 45 & 3.721 & 72 & 0.075 \\
\hline 5 & 0.29 & 46 & 0.009 & 73 & 0.014 \\
\hline 6 & 0.035 & 47 & 0.201 & 74 & 1.948 \\
\hline 7 & 0.273 & 48 & 0.002 & 74 & 1.466 \\
\hline 8 & 0.67 & 46 & 0.003 & 75 & 0.208 \\
\hline 9 & 1.2 & 48 & 0.136 & 76 & 0.005 \\
\hline 10 & 0.409 & 49 & 0.052 & 77 & 0.122 \\
\hline 11 & 0.221 & 37 & 0.551 & 78 & 0.006 \\
\hline 12 & 0.297 & 38 & 1.275 & 79 & 0.372 \\
\hline 13 & 0.075 & 39 & 1.334 & 80 & 0.134 \\
\hline 14 & 0.122 & 40 & 0.155 & 81 & 0.012 \\
\hline 15 & 0.054 & 41 & 0.258 & 82 & 0.119 \\
\hline 16 & 0.604 & 42 & 0.105 & 83 & 0.304 \\
\hline 17 & 0.021 & 50 & 0.052 & 84 & 0.169 \\
\hline 18 & 1.918 & 51 & 0.027 & 85 & 0.057 \\
\hline 19 & 0.598 & 52 & 0.031 & 86 & 0.125 \\
\hline 20 & 0.429 & 53 & 0.233 & 87 & 0.97 \\
\hline 21 & 0.398 & 54 & 0.007 & 88 & 0.026 \\
\hline
\end{tabular}


Global Journal of Engineering and Technology Advances, 2021, 06(02), 024-041

\begin{tabular}{|l|l|l|l|l|l|}
22 & 0.078 & 55 & 0.758 & 89 & 0.076 \\
\hline 23 & 0.048 & 56 & 0.263 & 90 & 0.011 \\
\hline 24 & 0.021 & 57 & 0.407 & 91 & 0.841 \\
\hline 25 & 0.122 & 58 & 1.147 & 92 & 1.776 \\
\hline 26 & 0.431 & 59 & 0.097 & 93 & 0.27 \\
\hline 27 & 0.643 & 60 & 0.386 & 94 & 0.033 \\
\hline 28 & 0.014 & 61 & 0.015 & 95 & 0.202 \\
\hline 29 & 0.202 & 62 & 0.306 & 96 & 0.032 \\
\hline 30 & 0.172 & 63 & 1.233 & 97 & 0.083 \\
\hline 31 & 0.011 & 64 & 0.472 & 98 & 0.031 \\
\hline 32 & 0.074 & 65 & 1.112 & 99 & 0.034 \\
\hline 33 & 0.003 & 66 & 1.147 & 100 & 0.981 \\
\hline 34 & 0.011 & 67 & 0.681 & 101 & 1.442 \\
\hline 35 & 0.401 & 68 & 0.021 & 102 & 0.877 \\
\hline 103 & 0.508 & 117 & 0.027 & 110 & 0.163 \\
\hline 104 & 0.101 & 106 & 0.038 & 111 & 0.269 \\
\hline 105 & 0.023 & 107 & 0.83 & 112 & 0.077 \\
\hline 115 & 0.071 & 108 & 0.215 & 113 & 0.074 \\
\hline 116 & 0.023 & 109 & 0.664 & 114 & 0.085 \\
\hline
\end{tabular}

\subsection{Optimization of the Model}

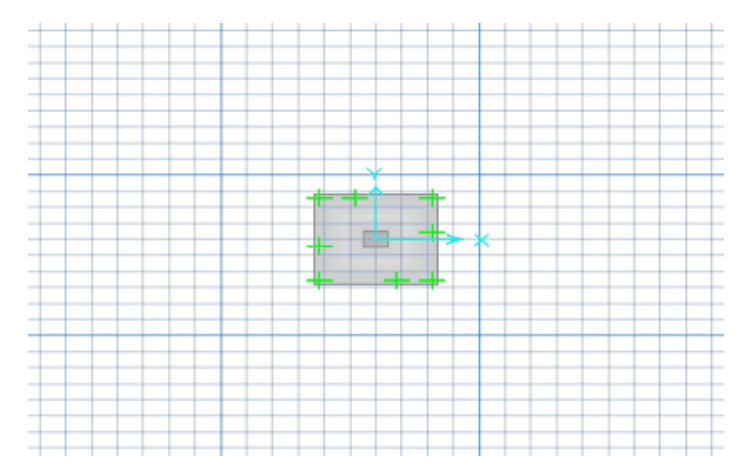

Figure 7 Finite element model for isolated footing

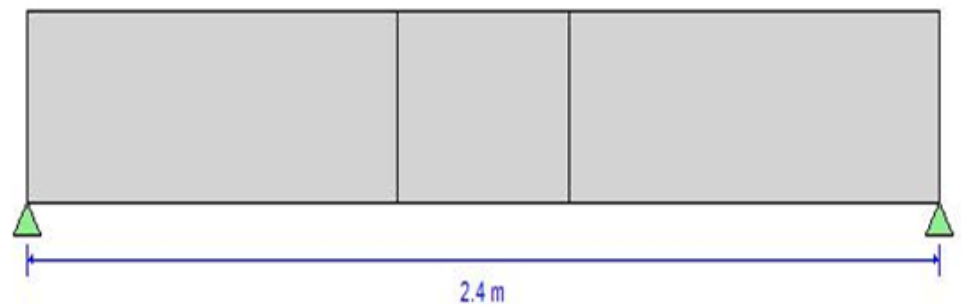

Figure 8 Finite element model for isolated footing 
Global Journal of Engineering and Technology Advances, 2021, 06(02), 024-041

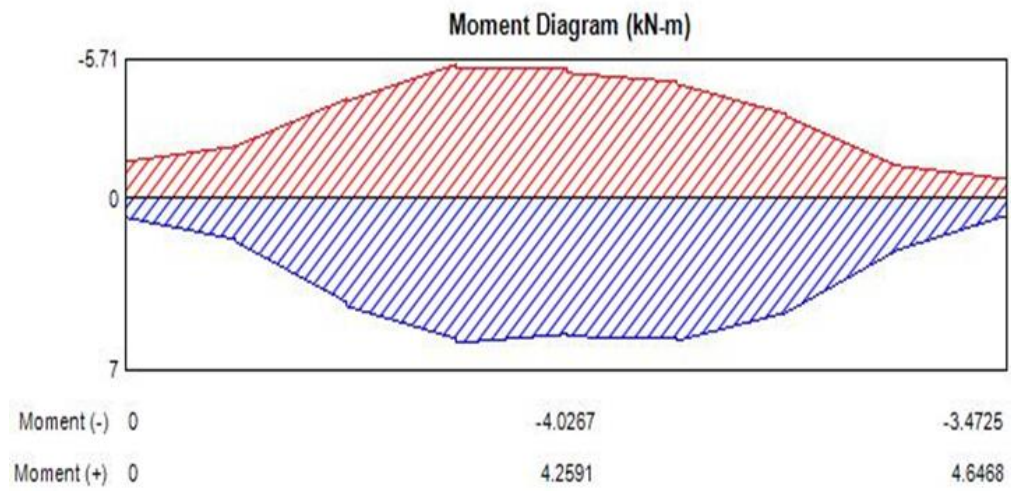

Figure 9 Moment diagram of isolated footing showing the maximum point of stress

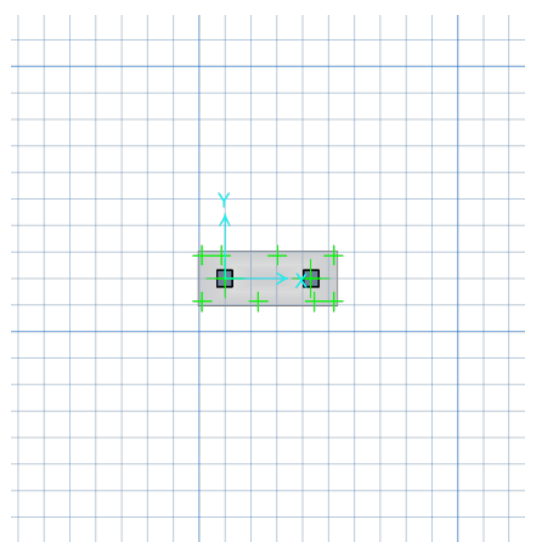

Figure 10 Finite element model for combined footings

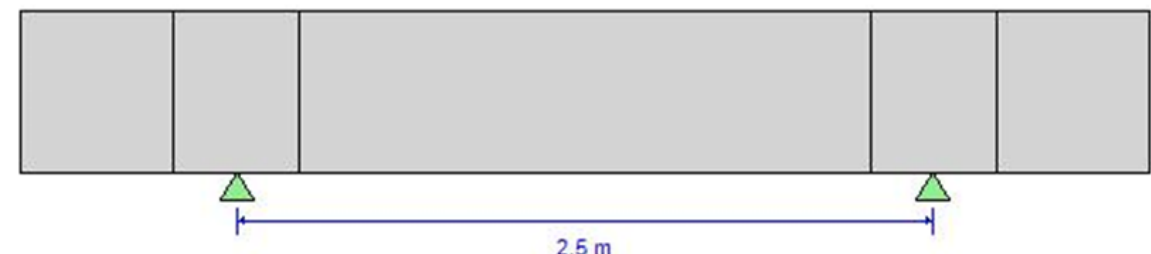

Figure 11 Finite element model for combined footings showing the distance between the columns.

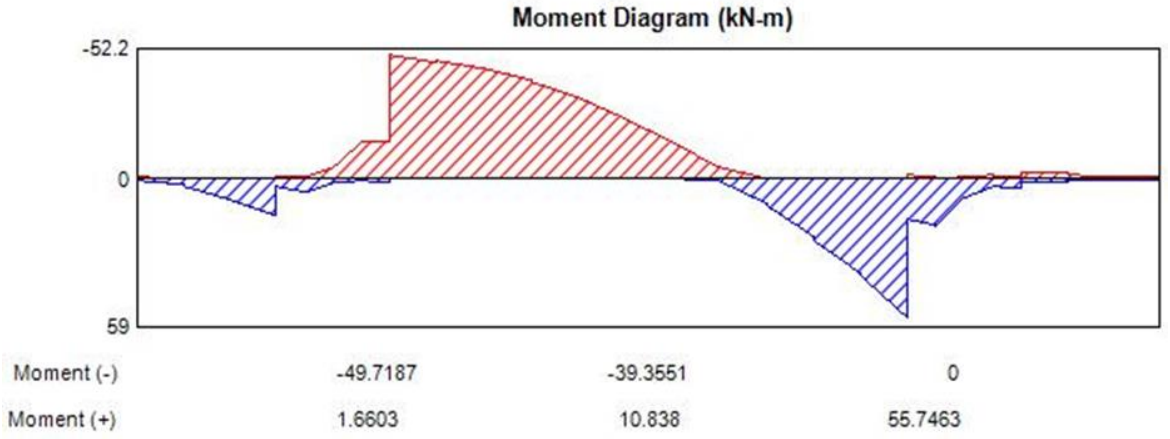

Figure 12 Bending moment diagram for the combined footings 


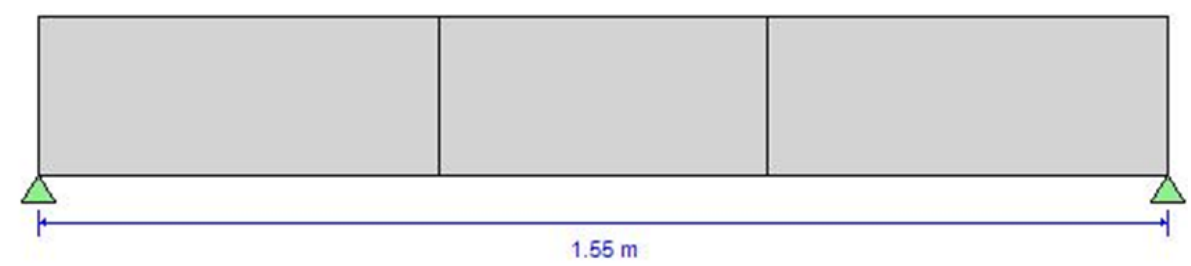

Figure 13 Showing the model at a distance from the column

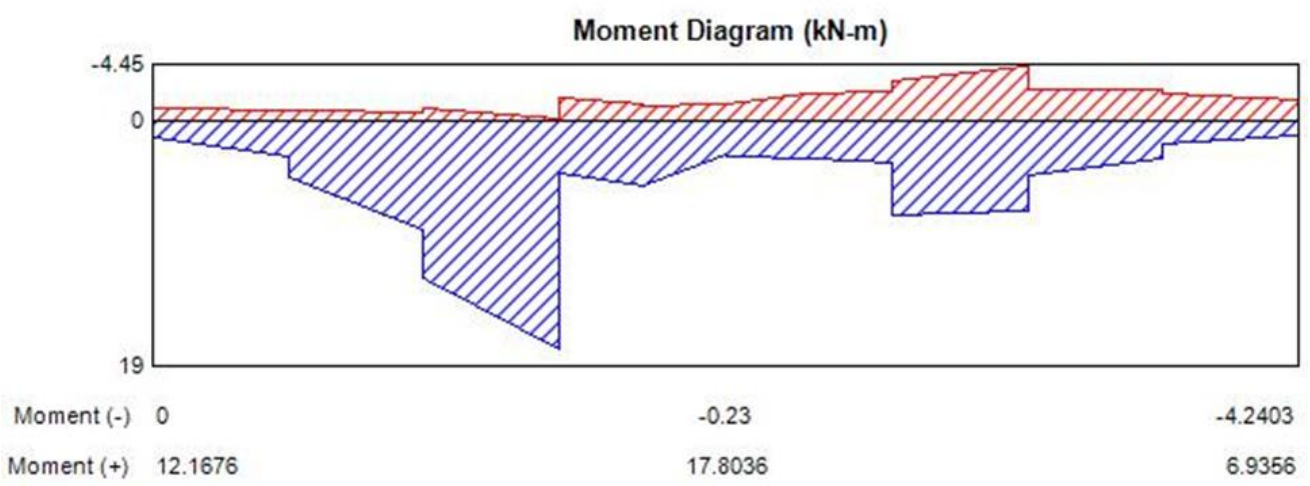

Figure 14 Bending moment diagram of the distance from the column

From the figure stated above in section 4.2 i.e. figure $1.8-2.5$ it is noted that when the spacing between footings is changed, the maximum moment is always at the footing center and increase with increasing in footing spacing. The reaction of the soil pressure and the applied force on the footing yield equilibrium and state stability in isolated footing.

\section{Conclusion}

Based on the finite-element analysis of foundations resting on footing embedded in homogeneous linear elastic soil, the following conclusions could be drawn

- $\quad$ The displacement reached its maximum value at the same frequency with a higher node.

- The result indicate that for the footing of foundation considering the meshing spacing ration of (200mm) does not reveal the optimum spacing with regard to displacement.

- When the spacing between footings is changed, the maximum normalize moment factor $I_{m}$ is always at the footing center and increase with increasing in footing spacing, Im decrease by about $67 \%$ of the footing spacing of $1.675 \mathrm{~m}$ and increase by about $18 \%$ for the $2.5 \mathrm{~m}$ spacing, This is because the span supported by the footing increases with increasing spacing, leading to greater moments. The increase in $I_{m}$ with footing length can be attributed to the increase in the unsupported length within the footing, which leads to an increase in the moment.

- The dimensionless displacement factor $I_{z}$ decreases markedly as the meshing increases, reflecting the increase in displacement with increasing footing spacing.

\section{Recommendations}

Based on the analysis of the footing modeling it is deduce that

- For a footing to be suitable and appropriate it is necessary to have a numerous mesh in order to achieve a good analysis.

- For combine footings the spacing should not exceed $2.5 \mathrm{~m}$ in order to achieve a good stress analysis for the design.

The size of the footing should vary with the magnitude of load and column size that the footing supports. 


\section{Compliance with ethical standards}

\section{Acknowledgments}

All thanks to the Almighty God for the financial grace and wisdom for embarking and completing this research. I sincerely appreciate all authors whose research articles were cited.

\section{Disclosure of conflict of interest}

They was no conflict of interest during the research.

\section{References}

[1] Bowles JE. Foundation Analysis and Design, 5th edn. McGraw-Hill, New York, NY, USA. 1977.

[2] David VH. Fundamental of Finite Element Analysis. New York: McGraw-Hill. 2004.

[3] Abdel-Fattah M, Saber M, Kantoush SA, Khalil MF, Sumi T, Sefelnasr AM. A Hydrological and Geomorphometric Approach to Understanding the Generation of Wadi Flash Floods. Water. 2017; 9(7): 553.

[4] Farrokhzad F, Choobbasti AJ. Assessing the Load Size Effect in the Soil (Under Single Foundation) Using Finite Element Method. International Journal of Soil Science. 2011; 6(3): 209-216.

[5] Hutton JL, Eccles MP, Grimshaw JM. Ethical issues in implementation research: a discussion of the problems in achieving informed consent. Implement Sci. 2008; 3: 52.

[6] Kharagpur. Version 2 CE IIT Foundations - Theory and Design. 2017.

[7] Kouzer KM, Kumar J. Ultimate bearing capacity of a footing considering the interference of an existing footing on sand. Geotech. Geol. 2010; 28: 457-470.

[8] Kumar J, Bhattacharya P. Bearing capacity of interfering multiple strip footings by using lower bound finite element limit analysis. Comput. Geotech. 2015; 37: 731-736.

[9] Madan G. Kittur, Ronald L. Huston. (November 1989) Mesh Refinement in Finite Element Analysis by Minimization of the Stiffness Matrix Trace.

[10] Oyenuga VO. Simplified Reinforced Concrete Design, Asros Limited, Lagos. 2001.

[11] SAFE. Safe manual, version 16.0.1. CSC, IP, Inc. 2016.

[12] Satish KSR, Santhian KAR. Design of Steel Structure. 2010.

[13] Fattah A, M Sharafi M, Masoudi R, Shahverdi A, Esmaeili V, Najafil A. Carnitine in rooster semen cryopreservation: flow cytometric, biochemical and motion findings for frozen-thawed sperm. Cryobiology. 2017; 74: 148-153. 